\title{
Memoria y creación musical: Suyai. La esperanza también es un canto
}

\author{
por \\ Fernanda Ortega Sáenz \\ Departamento de Música, \\ Universidad Metropolitana de Ciencias de la Educación, Chile \\ lfortega@uc.cl
}

Los primeros días de julio de 2015 se alcanzó un logro para el fútbol nacional, al ganar el equipo de Chile la Copa América 2015. El Estadio Nacional se llenó de banderas chilenas -donadas por un novedoso tipo de personaje local, el filántropo-y la celebración en dicho recinto fue seguida por millones de chilenos por la televisión. En una de esas imágenes, recortada luego en decenas de fotografías, al fondo en la estructura del Estadio se pudo ver con una tenue claridad la siguiente frase escrita en grandes letras: "Un pueblo sin memoria es un pueblo sin futuro". Dicha frase fue colocada en homenaje a las víctimas de la represión ocurrida en el Estadio Nacional en 1973 durante los primeros meses de la dictadura militar en Chile. Probablemente es la primera vez que ha sido expuesta masivamente para quienes no frecuentamos dicho recinto.

El día 18 de septiembre de 2014 se estrenó en Buenos Aires la obra Suyai. La esperanza también es un canto, primera ópera del académico del Departamento de Música y Sonología de la Universidad de Chile, el compositor Eduardo Cáceres Romero. Dicha obra cubre el período histórico que va desde los días previos al golpe militar el 11 de septiembre de 1973 hasta el plebiscito del 5 de octubre de 1988 que permitió la vuelta a la democracia en Chile. Es un período de ínfima duración para las transformaciones de la naturaleza, recordando la concepción de tiempo histórico de Fernand Braudel. No obstante tiene una extrema y profunda duración para nuestro país, aunque esta permanencia ocurra de manera casi soterrada. En el estreno de la ópera de Eduardo Cáceres Romero, sin los millones de espectadores que observan los medios masivos que cubren eventos mediáticos, el público pudo oír en su inicio el audio del último discurso de Salvador Allende en el palacio de gobierno de La Moneda. Como fondo se proyectó la imagen de una mujer en escena, que cambiaba sus vestimentas a las de una mujer mapuche y que en los momentos más intensos del discurso realizó un ritual de machi cantando en mapudungun.

El proyecto de creación de la ópera Suyai. La esperanza también es un canto surgió en el marco de invitaciones y visitas previas del compositor Eduardo Cáceres Romero a Argentina. Los contactos se originaron a partir de una invitación a la Universidad de La Plata en 2009. De este modo surgió una red de actividades posteriores que culminaron en el inédito encargo que la Secretaría de Cultura de la Nación Argentina hizo a Cáceres para que compusiera esta obra. El estreno se realizó en la Sala Guastavino del Centro Nacional de la Música, barrio San Telmo, con dos funciones los días 19 y 20 de septiembre de 2014 y un preestreno el día 18, en el marco del IV Ciclo Iberoamericano de Ópera Contemporánea que organizó dicha Secretaría de Cultura.

La obra contó con la dirección musical de Valeria Martinelli, la participación de los bailarines Koki y Pajarín Saavedra y la regie de Lizzie Waisse. Fue interpretada por músicos del Centro Nacional de la Música de Argentina, varios de ellos miembros de la Orquesta Sinfónica Nacional, de la Orquesta del Teatro Colón y los cantantes de ambas orquestas. Fue protagonizada por los solistas Tamara Odón (contralto), Carlos Ullán (tenor) y Nelson Ayoub (bajo). El elenco se completó con siete instrumentistas, diseño escenográfico y vestuario de Stella Maris Müller y diseño de iluminación de Ernesto Bechara. El montaje estuvo además apoyado por proyecciones en video de fragmentos del documental La batalla de Chile de Patricio Guzmán y obras del artista plástico Carlos Alonso. 
El libreto es obra de la destacada escritora peruana Maritza Núñez. Amiga personal de Cáceres, entre ambos analizaron cómo agrupar en una ópera los intereses del compositor en el marco de este encargo. Las temáticas comunes entre Chile y Argentina, en relación con los procesos históricos de las dictaduras militares, permitieron articular varios pasajes del relato. Este se focaliza en la historia de una mujer que es participante activa del periodo de la Unidad Popular, y que estando embarazada, es detenida durante el golpe militar. Su hija, luego de nacer en reclusión es separada de ella y es adoptada por una machi del pueblo originario mapuche. Recibe el nombre de Suyai, palabra mapuche que simboliza la esperanza y que proporciona el título a la obra.

En el libreto hay una insistencia en las referencias de época. Probablemente se consideró necesario remarcar los vínculos históricos directos entre lo que se narra en la ópera y la memoria de un posible espectador objetivo, centrado en ambos países del cono sur americano. Esta insistencia por momentos se hace más evidente. El devenir de la ópera se acompaña con alusiones a los conflictos e hitos esenciales del período histórico elegido, apoyados con extractos de discursos y frases características en una suerte de recuento o enumeración de hechos y personajes. A modo de ejemplo, mientras el piano actúa como nexo y base instrumental en el inicio, la escena se sitúa en el "Barrio Providencia" de Santiago, con la indicación de la fecha 08/09/1973 en letras tipo stencil a semejanza de lo que se usaba en la época para la propaganda política, pero que en la ópera aparecen de neón. Una mujer embarazada señala que "va a la marcha" y que son "los tres años de la UP, los más felices de mi vida”. A esto se agregan sones marciales constantes de la percusión y la imagen de Augusto Pinochet para el golpe militar que aparece, se acerca y se hace enorme.

A continuación se hace alusión a los campos de reclusión, a las terribles violaciones a los derechos humanos, a los mandos militares y a diversas situaciones dramáticas vividas en ese oscuro período en Chile y en Argentina. La trama abarca hasta finales de los años ochenta con la campaña y triunfo del NO en Chile. Aparece el recordado video de la franja del NO proyectado en escena. La protagonista se prepara para encontrarse por primera vez con su hija Suyai en la "marcha de la alegría" y, señala que "Chile nos pertenece a todos", vestida con la característica camiseta con el arcoíris del NO. Nos resulta a decir verdad algo incómodo ver al final de la ópera a todos los cantantes y músicos del ensamble vestidos con dicha camiseta y el arcoíris.

A partir de esta exhibición explícita de un período de la historia de Chile, surge la pregunta de si es posible encontrar otras formas de representar, si es que este término está permitido en la música, un conflicto histórico o el compromiso de un compositor. Carecemos del espacio para entrar en este inagotable dilema. No obstante, la pregunta evoca los intentos explícitos de ligar la música con ideas políticas o extramusicales característicos de los años sesenta y setenta. Estos pueden haber tendido a realizar un arte didáctico, que buscaba enseñar y transmitir al público ciertos ideales o visiones acerca de episodios de la historia de Chile. Nestor García Canclini, al referirse a las políticas culturales latinoamericanas que han buscado abolir la distancia entre artistas y espectadores, las denomina como una contextualización pedagógica. Con esta, se trata de acabar con el monopolio del saber por los especialistas, de modo de permitir a los neófitos, en un tratamiento acelerado, llegar a aprender lo que les falta para ser artistas o por lo menos estar tan informados como ellos. Para el caso de los museos, García Canclini señala cómo se llenaron de carteles instructivos, señales de tráfico, visitas guiadas en varios idiomas y menciona luego, cómo se situaron los cuadros y las esculturas en medio de referencias contextuales que ayudarían a entenderlos ${ }^{1}$.

1 García Canclini 1990: 129. 
El mismo autor profundiza en este punto al identificar una suerte de teatralización del patrimonio en los países modernos en América Latina. Es decir, para que las tradiciones sirvan hoy de legitimación a quienes las construyeron o a quienes se las apropiaron, es necesario ponerlas en escena. El patrimonio existe como fuerza política en la medida en que es teatralizado: en conmemoraciones, monumentos y museos ${ }^{2}$. Podríamos agregar que la memoria ha tendido a volverse patrimonio en la música cuando se ha buscado hacer de ambas una herramienta para transmitir de manera explícita elementos extramusicales. Si bien el riesgo que han enfrentado estas iniciativas está en que lo propio de la música se extravíe. Para el caso de enfrentar una deuda con la memoria reciente de Chile, que asuma el esfuerzo de la recuperación de un relato que se ha fracturado, se constata que en el caso de la música docta la ópera es probablemente el género que permite la manera más directa de hacerlo.

En tal sentido, la obra de Cáceres representaría la continuidad de una línea de creación desarrollada en Chile a partir de mediados del siglo XX. Luis Merino Montero propone varias etapas para la comprensión y el estudio de la música de tradición escrita en Chile ${ }^{3}$. Entre ellas figura la comprendida entre 1948 y 1973, definida como la época más brillante de la historia de la música nacional ${ }^{4}$, con un florecimiento de un pluralismo no restringido de tendencias y una multiplicidad de propuestas creativas de gran variedad e interés ${ }^{5}$. Entre las líneas renovadoras particulares de esta etapa ${ }^{6}$, pertinentes a este trabajo, figuran aquellas propuestas que plantearon una notoria inquietud ética del compositor ante la historia y la sociedad de Chile, Latinoamérica o Europa, y que se expresaron en general mediante un género sinfónico-vocal y épico-narrativo que se entronca con la línea de El sobreviviente de Varsovia de Arnold Schoenberg, o mediante la canción o la cantata con acompañamiento instrumental ${ }^{7}$. Figuran aquí compositores como Acario Cotapos Baeza, Eduardo Maturana Araya, Gustavo Becerra Schmidt, León Schidlowsky Gaete, Fernando García Arancibia, Luis Advis Vitaglic y Sergio Ortega Alvarado.

En el siguiente período que abarca desde 1973 a 1990, fundamentalmente bajo el alero de la Universidad de Chile y contando como maestro al compositor Cirilo Vila Castro, según Luis Merino Montero se formó una importante generación de creadores, entre ellos están Andrés Alcalde Cordero, Alejandro Guarello Finlay y quien nos convoca ahora, Eduardo Cáceres Romero. Sobre la base de categorizar de acuerdo con la fecha de inicio de su presencia creativa, Cáceres Romero habría debutado en la década de $1970^{8}$. Es posible reconocer en este período, de acuerdo con Merino Montero, dos tendencias que, de manera diferente pero complementaria, buscaron afianzar una identidad en lo chileno y en lo latinoamericano más que en lo europeo. Esto se manifestó tanto en las múltiples propuestas basadas en manifestaciones chilenas o latinoamericanas, como también en el empleo de música de culturas aborígenes extintas de Chile ${ }^{9}$.

La tradición operática en Chile tiene sus inicios en las primeras décadas del siglo XIX. Antes de 1973 se puede reconocer una producción de óperas nacionales, que es escasa pero relativamente regular y sin grandes pausas, a pesar que no todas fueron estrenadas. A finales de los años sesenta y comienzos de los setenta el género cantata toma fuerza y ocupa

\footnotetext{
2 García Canclini 1990: 151.

3 Merino 1993.

4 Merino 1993: 635.

5 Merino 1993: 636.

6 Merino 1993: 637.

7 Merino 1993: 637.

8 Merino 1993: 638

9 Merino 1993: 638
} 
de alguna manera el lugar de la ópera. A partir de 1973 se produce un quiebre en esta regularidad, por las condiciones generales históricas en que entra el país. Habrá que esperar hasta la década de los ochenta para que el género operático sea retomado, aunque será más bien por parte de compositores chilenos que están en el extranjero, principalmente a causa de un exilio voluntario u obligatorio. Se aprecia entonces una línea de composiciones que retoman el compromiso social y ético mencionado antes, si bien en un contexto que casi lo hacía obligatorio. Se destaca la ópera Expulsados del país (1978) que escribiera Juan Allende-Blin en Alemania, en homenaje al tenor Hanns Stein Klein, y tomando como base la propia experiencia del cantante.

Posteriormente se encuentran composiciones con alusiones tanto políticas como a un referente indígena nacional, ambas temáticas retomadas por Cáceres en su obra. A este respecto se pueden señalar las siguientes obras: El camino del inca (1980) del compositor Marcelo Saxton Soto, estrenada en el Liceo Manuel de Salas; Nel mundo del rekuperare (1982) de Jorge Martínez Ulloa, y la ópera Viudas (Widows) op. 101 (1987-1990) del compositor Juan Orrego Salas ${ }^{10}$. Esta última se acerca más a nuestro asunto. Basada en la novela homónima de Ariel Dorfman, se agrega a las escasas obras del género escritas por compositores chilenos y está inspirada en las trágicas muertes o desapariciones de personas acaecidas en el país, con una perspectiva de amor y reconciliación agregada al texto por el mismo compositor ${ }^{11}$.

Si se revisa la década de los noventa desde que se recupera la democracia hasta hoy, es sintomática la diferencia en las temáticas elegidas por los compositores que han escrito óperas. Consideramos que esto se debe a que en varios casos quienes han retomado el desafío del género operático corresponden a las nuevas generaciones, incluidos los más jóvenes compositores, los que ya no se vinculan directamente con la tradición fracturada en 1973. Ellos se ubican en un contexto completamente distinto sociopolítico y económico, sumergido en la globalización, las nuevas tecnologías y forman parte de lo que Jorge Larraín define como una identidad fracturada ${ }^{12}$. Se podrá argumentar que en El Pukará de Carlos Zamora Pérez (1997) y en obras similares de otros compositores jóvenes el asunto político o indigenista está presente, cosa que no pretendemos negar; pero en términos generales no es de la forma explícita que se desarrolló anteriormente en la música docta en Chile. En este sentido, Cáceres Romero retoma en su ópera esta continuidad de la música de tradición escrita nacional.

En lo que respecta a la incorporación de la machi como personaje nexo en la ópera Suyai, el acercamiento de Cáceres a la cultura mapuche no es algo nuevo ni pasajero, sino que ha sido cultivado desde hace años tanto a nivel composicional como personal. El creador ha señalado cómo la importancia de la cultura mapuche en vastas regiones de Chile ha sido sistemáticamente ocultada y desconocida en nuestra historia como nación y contra eso quiere apuntar en esta y en otras de sus composiciones. En tal sentido, es valioso mencionar su obra Cantos ceremoniales para aprendiz de Machi (2004) para coro de voces femeninas, la que se ha convertido en un referente del repertorio indigenista nacional de los últimos años.

La ópera de Cáceres Romero tiene una duración aproximada de una hora y diez minutos. Consta de una obertura, tres actos y un epílogo, y está escrita para un ensamble de cámara. Algunos pasajes evocan ciertos giros y ritmos característicos de la Historia del soldado de Igor Stravinski, una obra referente de la música escénica para pequeño formato centrada en un conflicto de guerra. La ópera de Cáceres Romero se inclina a paralelismos musicales

10 Se toma como referencia el listado presentado en el minisitio La ópera en Chile (1830-2012) del portal Memoria Chilena. Ver bibliografía.

11 Merino 2003: 46.

12 Larraín 2005. 
y ostinatos insistentes con pocos momentos de silencios. A lo largo de ella se alternan pasajes de corte operático tradicional, con personajes en escena que siguen una línea narrativa con acompañamiento musical, con otros de recuento histórico, en que las propias voces de Salvador Allende y Augusto Pinochet cubren la escena con sus palabras. Asumiendo el rol de enfatizar la situación represiva y marcial, la música varía poco motívicamente. Durante un largo momento se mantiene un ostinato de quinta Do-Sol que vuelve a evocar a Stravinski. Más adelante aparece un extenso pedal entre las notas Do-La b-Sol. Luego de algunas escenas de momentos históricos nuevos, como la alusión al centro de reclusión de Tres Álamos, aparece otro pedal con ritmos básicos y notas insistentemente repetidas. $\mathrm{Al}$ respecto, se podría haber aprovechado más el ensamble instrumental, aunque este sea pequeño, con mayor desarrollo de texturas, contrapuntos o melodías en los instrumentos. La primacía sin embargo la tienen los pasajes y la escritura rítmica, en métricas simples. Esto lo entendemos como resultado de la búsqueda de una idea marcial como base musical a lo que sucede en la escena.

¿Puede la música ayudar a recuperar la memoria histórica de quienes la oyen? ¿Debe la creación musical cumplir ese papel? Las respuestas pueden ser tanto numerosas como contradictorias. No obstante si hay un género musical apto para ser considerado en este debate este es justamente la ópera, porque la música se relaciona estrechamente con las palabras en el marco de la acción dramática. Creemos que no estaba dentro de los propósitos de Eduardo Cáceres Romero el poner en crisis los límites del género, pero sí buscó reponer en algo la memoria y remover el cómodo estado de olvido en que permanece la sociedad chilena.

Finalmente, todo esto se refleja en lo musical e influye en el esfuerzo que un auditor activo pueda o no hacer en función de lo que se le está presentando. El mismo García Canclini señala acerca de la recepción del arte, que toda escritura, todo mensaje, están plagados de espacios en blanco, silencios, intersticios, en los que se espera que el lector produzca sentidos inéditos ${ }^{13}$. Las obras suelen incluir instrucciones más o menos veladas, dispositivos retóricos, para inducir lecturas y delimitar la actividad productiva del receptor $^{14}$, por lo que consideramos no es necesario guiarlo demasiado exhaustivamente. Es loable que un compositor quiera colaborar en saldar la deuda de memoria histórica de Chile. No obstante se puede discutir el modo de participar de esta tarea de acuerdo con nuestras propias posturas estéticas, las que, en determinadas épocas, pudieran haber sido entendidas como trincheras artísticas.

Una vez cumplida la labor a la que nos impela de modo silencioso aquella frase señalada al inicio, "Un pueblo sin memoria es un pueblo sin futuro", se puede esperar que algún día no será necesario entregar al espectador una memoria teatralizada para que recuerde lo acaecido en nuestro país. Para García Canclini, la teatralización del patrimonio es el esfuerzo por simular que hay un origen, una sustancia fundante, en relación con la que deberíamos actuar hoy ${ }^{15}$. Apuntamos con esto al delicado asunto de hacernos cargo desde el arte del vacío de la memoria nacional mediante intentos individuales, esporádicos, a veces heroicos en su búsqueda de abordar todas las deudas históricas pendientes, debido a la ausencia de políticas públicas culturales y educacionales que asuman estas responsabilidades a gran escala. Consideramos que el arte puede colaborar en esto pero en ningún caso debe hacerse cargo de esta tarea, a riesgo de terminar teatralizando esa memoria. ¿Pero cuál sería el límite al teatralizar nuestro pasado histórico y hacer un rescate de nuestra memoria

13 García Canclini 1990: 142.

14 García Canclini 1990: 143.

15 García Canclini 1990: 152. 
mediante el arte de manera tan explícita? El límite sería, recordando a Walter Benjamin, la estetización de la memoria, la estetización de nuestra historia.

Creemos importante y necesario destacar de nuestro hermano país de Argentina, el que, gracias a su Secretaría de Cultura de la Nación, tenga un ciclo iberoamericano de ópera contemporánea y más aún, que en 2014 se haya realizado su cuarta versión. Es algo que ni en sueños logramos imaginar en nuestras tierras y que debiéramos buscar la forma de revertir, junto con aplaudir la iniciativa del ministerio argentino que realizó el encargo de la obra a Cáceres. Dichos encargos en nuestro país son de una extrema rareza. Por contraste, en muchos países europeos o en Norteamérica los compositores logran vivir económicamente de estos encargos, que no necesariamente requieren de largas y engorrosas postulaciones a fondos concursables de resultados inciertos como es el caso en nuestro país. Junto con impulsar la creación de nuevas obras, no se debe olvidar la existencia de más de una docena de óperas escritas en Chile desde sus inicios, las que esperan ser estrenadas en algún hipotético momento futuro.

La ópera de Eduardo Cáceres Romero continúa y completa un camino abierto a mitad del siglo XX que quedó interrumpido por el golpe militar, y que fue reemplazado durante los años de dictadura por la Cantata y la Nueva Canción Chilena. Más allá de que la línea que ha tomado la ópera en Chile en el presente siglo XXI parte de un camino distinto, con otras raíces, o que se nutre más bien de un universo musical mediatizado con raíces hidropónicas como propone lúcidamente Juan Pablo González ${ }^{16}$, la obra de Cáceres Romero prosigue una vía natural creativa e ideológica, retomando esa línea truncada y participando en saldar una deuda histórica, que está pendiente y que es con la memoria de Chile y con toda nuestra estructura imaginaria y social.

\section{BIBLIOGRAFÍA}

García Canclini, Néstor

1990 Culturas híbridas, estrategias para entrar y salir de la modernidad. México: Grijalbo.

González Rodríguez, Juan Pablo

2013 Pensar la música desde América Latina. Santiago: Universidad Alberto Hurtado.

La ópera en Chile (1830-2012). Minisitio del portal memoria chilena: http:/ /www.memoriachilena.cl/602/w3-article-100675.html

LARRAÍn, JORGE

2005 ¿América Latina moderna? Globalización e identidad. Santiago: LOM.

Merino Montero, Luis

1993 "Chile. Creación musical de arte en el Chile independiente", Diccionario de la Música Española e Hispanoamericana. Director y Coordinador General: Emilio Casares Rodicio. Volumen 3. Madrid: SGAE (Sociedad General de Autores y Editores), pp. 628-639.

2003 “1973-2003: treinta años”, Revista Musical Chilena, LVII/199 (enero-junio), pp. 39-56. Disponible en www.revistamusicalchilena.uchile.cl

16 González 2013: 270. 